\title{
Padrão de Interação Humano-Computador em sistemas da Câmara dos Deputados
}

\author{
A criação de um padrão que se integra aos produtos de software \\ Gustavo de Lima Santos \\ Diretoria de Inovação e TI \\ Câmara dos Deputados \\ Brasília DF Brasil \\ gustavo.lima@camara.leg.br \\ Maurício Agostinho \\ Carneiro da Silva \\ Diretoria de Inovação e TI \\ Câmara dos Deputados \\ Brasília DF Brasil \\ mauricio.silva@camara.leg.br \\ Francisco Edmundo de \\ Andrade \\ Diretoria de Inovação e TI \\ Câmara dos Deputados \\ Brasília DF Brasil \\ francisco.edmundo@camara.leg.br
}

\begin{abstract}
RESUMO
Buscando aprimorar a experiência do usuário na operação de sistemas, no âmbito da Câmara dos Deputados (CD), foi implementado pela Diretoria de Inovação e Tecnologia da Informação (Ditec) o chamado Padrão de Interações Ditec (PIC). Trata-se de um padrão de interação humano-computador que se integra aos produtos de software, e cuja adoção tem promovido o desenvolvimento de interfaces de usuário consistentes, responsivas e acessíveis, contornando a questão do nível de conhecimento heterogêneo entre as equipes de desenvolvimento da Ditec. O PIC vem paulatinamente sendo adotado pelas equipes. Existem desafios a superar quanto a sua adoção. Os usuários de sistemas têm sido beneficiados com as novas interfaces. A adoção do padrão mostrou-se um meio eficaz para alcançar o aprimoramento almejado na experiência do usuário.
\end{abstract}

\section{PALAVRAS-CHAVE}

experiência do usuário, interação humano-computador, padrão de interação, usabilidade, acessibilidade

\section{DESCRIÇÃO DO PROBLEMA}

As dezenas de equipes de desenvolvimento da Ditec, responsável pelos sistemas da $\mathrm{CD}$, trabalham de forma autônoma, adotando definições próprias para as interfaces de usuário e apresentando níveis de conhecimentos distintos para o desenvolvimento delas. Isso forma um cenário onde se observa diversos sistemas desenvolvidos com interfaces nem sempre: responsivas (adaptáveis a diferentes tamanhos de tela); acessíveis (utilizáveis por qualquer pessoa, independentemente de sua condição física); e consistentes (cujos elementos comuns apresentam aparência e comportamento semelhantes nas diversas interfaces).

Permission to reproduce or distribute, in whole or in part, material extracted from this work, verbatim, adapted or remixed, as well as the creation or production from the content of such work, is granted without fee for noncommercial use, provided that the original work is properly credited. IHC 2019 - TRILHA IHC NA PRÁTICA, Outubro 21-25, 2019, Vitória, Brasil. In Anais Estendidos do XVIII Simpósio Brasileiro sobre Fatores Humanos em Sistemas Computacionais. Porto Alegre: SBC.

(C) 2019 by the author(s), in accordance with the terms of the Creative Commons Attribution-NonCommercial 4.0 International Public License (CC BY-NC 4.0).
A falta das três características citadas implica em prejuízo da experiência dos usuários, as cerca de 15 mil pessoas que trabalham na $\mathrm{CD}$ e que utilizam vários sistemas da organização. O usuário está sujeito a encontrar barreiras de acessibilidade, restrições quanto ao uso em dispositivos com telas pequenas, e dificuldades na operação dos sistemas pela falta de consistência.

\section{SOLUÇÃO}

A estratégia escolhida para evitar que novos sistemas fossem desenvolvidos com as lacunas apontadas (interfaces não responsivas, não acessíveis e inconsistentes), contornando a heterogeneidade de nível de conhecimento entre as equipes, foi a criação de um padrão corporativo para as interfaces de usuário dos sistemas. Esse padrão deveria contemplar os aspectos construtivos, visuais (de aparência) e os de interação humanocomputador [1,7] das interfaces. Deveria também oferecer aos desenvolvedores, além de templates e recomendações de uso, código reutilizável para ser integrado aos produtos de software. Essa integração faria com que os desenvolvedores fossem menos exigidos (em termos de conhecimento) no processo de implementação das interfaces com as características almejadas.

Foi criado, então, em 2017, o Padrão de Interações Ditec (PIC), para utilização no desenvolvimento de novos sistemas da CD. O PIC foi projetado considerando a recomendação HTML5 [2] do World Wide Web Consortium (W3C), as diretrizes para acessibilidade WCAG 2.0 [3] e os padrões WAI-ARIA [4] para desenvolvimento de aplicações web ricas e acessíveis.

Percebeu-se, à época, que frameworks como Bootstrap [5] e Foundation [6] forneciam suporte à criação de páginas responsivas, mas delegavam ao desenvolvedor as decisões a respeito de como a interface deveria ser apresentada em função do tamanho da tela. Além disso, esses frameworks possuíam lacunas de acessibilidade por implementar somente em parte os padrões WAI-ARIA e as diretrizes WCAG. Por fim, embora estabelecessem definições de aspectos visuais, eles davam liberdade ao desenvolvedor para alterar cores, tamanhos e posicionamento dos elementos de interface. A equipe responsável pela concepção do padrão considerou que, embora esses frameworks pudessem representar um bom ponto de 
partida, a simples adoção de um deles não seria suficiente para chegar ao resultado esperado. O PIC traz para si a responsabilidade de definir como uma página e seus componentes vão se apresentar nos diversos tamanhos de tela, e oferece componentes que atendem os padrões e diretrizes de acessibilidade, sem que o desenvolvedor back-end precise conhecer esses detalhes. Além disso, o PIC procura limitar as possíveis definições de aparência e comportamento de elementos comuns de interface, visando manter a consistência desejada.

O PIC define como cada página (código HTML) do sistema deve ser estruturada e fornece um conjunto de componentes de interface (widgets) configuráveis e reutilizáveis. Possui também a documentação destinada aos projetistas de interfaces e desenvolvedores, que orienta sobre a construção das páginas e o uso dos widgets, especificando inclusive em que situações cada um deles deve ser utilizado.

Cada sistema utiliza os widgets de acordo com sua necessidade. São exemplos: campo com sugestão de preenchimento; tabela com filtro; janela modal; formulário com validação de campos etc. Quanto a suas características acessíveis e responsivas, por exemplo, para uma tabela que possua ordenação: o mecanismo de ordenação se comunica com a árvore de acessibilidade do navegador web, e pode ser acessado por teclado; quando exibida em um dispositivo de tela pequena, terá uma aparência mais adequada ao espaço disponível. Os widgets possuem uma identidade visual comum entre eles, característica necessária para a obtenção da consistência desejada.

A arquitetura do PIC e suas relações com o desenvolvedor, aplicação e usuário pode ser vista na Figura 1.

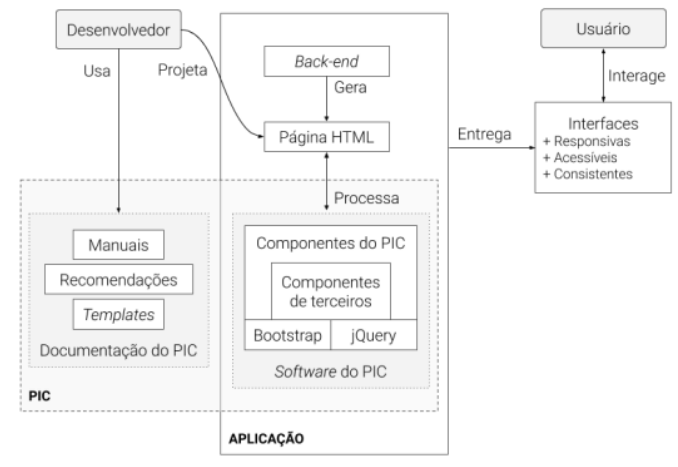

Figura 1: Arquitetura do PIC e suas relações externas

Ao adotar o padrão no desenvolvimento de um sistema, o desenvolvedor pode focar seus esforços no conteúdo e funcionalidades de negócio. As características dos elementos de interface são providas pelo PIC.

\section{RESULTADOS}

O PIC já foi adotado por ao menos uma dezena de sistemas em desenvolvimento ou já em uso. Naqueles que o adotaram plenamente, observa-se que as características almejadas estão incorporadas ao sistema, em benefício do usuário final.
Efetivamente, os resultados até o momento estão aquém do esperado quando da concepção do produto. Percebe-se que o ritmo de adoção do PIC foi mais lento que o previsto.

\section{REFLEXÃO}

Observa-se que os desenvolvedores encontram dificuldades especialmente em integrar o PIC a sistemas cuja arquitetura inclui frameworks de mercado que manipulam intensamente o HTML em client-side. Nesse cenário, existe uma concorrência pela manipulação de HTML entre o PIC e o framework utilizado. Isso pode ser uma causa do ritmo de adoção abaixo do esperado.

Ainda que o produto tenha sido concebido de forma a não exigir, do desenvolvedor, conhecimentos especializados para dar às interfaces as características buscadas, nota-se que um mínimo de conhecimento de HTML ainda é exigido. O código da página não contemplado por templates, por ser específico da aplicação, deve ser HTML bem escrito.

Há também o desafio de atender a necessidades específicas de cada sistema. Houve casos em que foi preciso criar elementos de interface não previstos no PIC. Constatou-se que dificilmente um padrão poderá antever todas as necessidades dos sistemas.

\section{CONCLUSÃO}

Criar um padrão corporativo de interação homem-computador tem se mostrado algo desafiador, mas também uma decisão acertada. Destaca-se um projeto de evolução de um sistema que incluía a adoção do PIC, caso em que os usuários, nos primeiros contatos com as novas interfaces, relataram como a mudança facilitaria o seu uso. Em outro, que está sendo desenvolvido no momento da redação desse artigo e tem como forte requisito a possibilidade de ser utilizado em smartphones, observa-se que a adoção do PIC tem se mostrado adequada para telas pequenas.

O PIC permite produzir sistemas com interfaces consistentes, responsivas e acessíveis, sem que seja necessário conhecimento especializado. Ele deve ser mantido e evoluído, buscando favorecer sua adoção e, em consequência, beneficiar cada vez mais usuários. É preciso também criar recomendações para que ele possa ser estendido sem prejuízo de suas características, quando houver uma necessidade específica de algum sistema.

Vislumbra-se que criar projetos-modelo com o PIC integrado a algumas arquiteturas comuns na instituição, bem como a realização de oficinas, ajudaria no sentido de ampliar essa adoção.

\section{REFERÊNCIAS}

[1] J Nielsen, 1994, Usability Engineering. Academic Press, Boston, MA, USA.

[2] HTML5, 2014. HTML5, https://www.w3.org/TR/2018/SPSD-html5-20180327/.

[3] WCAG 2.0, 2008. Web Content Accessibility Guidelines (WCAG) 2.0, https://www.w3.org/TR/WCAG20/.

[4] WAI-ARIA 1.0, 2014. Accessible Rich Internet Applications (WAI-ARIA) 1.0, https://www.w3.org/TR/wai-aria-1.0/.

[5] Bootstrap 3.3, https://getbootstrap.com/docs/3.3/.

[6] Foundation, https://foundation.zurb.com/.

[7] W Lidwell et al, 2010, Princípios Universais do Design. Bookman, Porto Alegre, RS, Brasil. 